OPEN ACCESS

Edited by:

Camillo Porcaro,

Istituto di Scienze e Tecnologie della

Cognizione (ISTC), Italy

Reviewed by:

Eugenie Roudaia,

Université de Montréal, Canada

Annalisa Setti,

University College Cork, Ireland

${ }^{*}$ Correspondence:

Allison M. McKendrick allisonm@unimelb.edu.au

Received: 27 October 2017 Accepted: 20 April 2018

Published: 09 May 2018

Citation:

Brooks CJ, Chan YM, Anderson AJ

and McKendrick AM (2018)

Audiovisual Temporal Perception

in Aging: The Role of Multisensory

Integration and Age-Related Sensory

Loss. Front. Hum. Neurosci. 12:192.

doi: 10.3389/fnhum.2018.00192

\section{Audiovisual Temporal Perception in Aging: The Role of Multisensory Integration and Age-Related Sensory Loss}

\author{
Cassandra J. Brooks, Yu Man Chan, Andrew J. Anderson and Allison M. McKendrick* \\ Department of Optometry and Vision Sciences, The University of Melbourne, Melbourne, VIC, Australia
}

Within each sensory modality, age-related deficits in temporal perception contribute to the difficulties older adults experience when performing everyday tasks. Since perceptual experience is inherently multisensory, older adults also face the added challenge of appropriately integrating or segregating the auditory and visual cues present in our dynamic environment into coherent representations of distinct objects. As such, many studies have investigated how older adults perform when integrating temporal information across audition and vision. This review covers both direct judgments about temporal information (the sound-induced flash illusion, temporal order, perceived synchrony, and temporal rate discrimination) and judgments regarding stimuli containing temporal information (the audiovisual bounce effect and speech perception). Although an age-related increase in integration has been demonstrated on a variety of tasks, research specifically investigating the ability of older adults to integrate temporal auditory and visual cues has produced disparate results. In this short review, we explore what factors could underlie these divergent findings. We conclude that both taskspecific differences and age-related sensory loss play a role in the reported disparity in age-related effects on the integration of auditory and visual temporal information.

Keywords: temporal perception, multisensory, audiovisual, integration, audition, vision, aging

\section{INTRODUCTION}

The normal aging process degrades both auditory and visual temporal perception, contributing to the difficulties older adults encounter with everyday tasks. For example, age-related impairments in speech comprehension and driving performance are associated with temporal processing deficits within audition (Gordon-Salant and Fitzgibbons, 1993; Füllgrabe et al., 2014; Babkoff and Fostick, 2017) and vision (Wood, 2002; Conlon and Herkes, 2008; Lacherez et al., 2014), respectively. However, many tasks stimulate both audition and vision. Therefore, this review targets how older adults combine these two sources of temporal information.

Integration binds auditory and visual stimuli into a unified percept, altering their perception relative to how they are perceived in isolation (Ernst and Bülthoff, 2004; Stein et al., 2009). Correctly inferring whether audiovisual integration is appropriate poses a behaviorally relevant challenge. Integration occurs when stimuli seem to share the same origin and one factor influencing this is close temporal correspondence between auditory and visual stimuli, such as similar onset (Lewald and Guski, 2003) and correlated temporal structure (Parise et al., 2012; Denison et al., 2013). 
Recent reviews indicate that aging increases integration across a range of perceptual domains and behaviors (Freiherr et al., 2013; de Dieuleveult et al., 2017). An age-related increase in integration of congruent auditory and visual cues may be beneficial, for example improving driving performance (Ramkhalawansingh et al., 2016). Conversely, integration of incongruent cues achieves a coherent percept at the cost of veridical perception and so greater integration could hinder everyday function in older adults. Interestingly, review of the literature specifically concerning the integration of temporal information indicates varied age-related effects, with reports of unaltered (e.g., Sommers et al., 2005; McGovern et al., 2014; Brooks et al., 2015) and decreased integration in older adults (e.g., Tye-Murray et al., 2011; Roudaia et al., 2013; Brooks et al., 2015). The perceptual change induced by integration depends on unisensory reliability (the precision of a sensory estimate of a property, as given by the inverse of its variance) and the brain's tendency to integrate auditory and visual cues (Ernst and Bülthoff, 2004; Odegaard and Shams, 2016). In this minireview, we consider whether age-related sensory loss (which affects unisensory reliability) and task-related differences (which may impact the integration process) explain the diversity of study findings.

\section{AGE-RELATED CHANGES IN UNISENSORY TEMPORAL PERCEPTION}

Physiological aging affects the auditory and visual pathways from the sensory periphery to the cortex, resulting in a decline in many aspects of temporal perception. Within audition, older age reduces sensitivity to temporal fine structure (Grose and Mamo, 2010; Moore et al., 2012; Füllgrabe, 2013; Füllgrabe et al., 2014), amplitude modulation (Takahashi and Bacon, 1992; He et al., 2008; Kumar and Sangamanatha, 2011; Füllgrabe et al., 2014; Wallaert et al., 2016) and frequency modulation (He et al., 2007; Grose and Mamo, 2012; Wallaert et al., 2016). Older adults exhibit impaired auditory gap detection (Snell, 1997; Strouse et al., 1998; Heinrich and Schneider, 2006; Humes et al., 2009; Kumar and Sangamanatha, 2011) and duration discrimination (Fitzgibbons and Gordon-Salant, 1994; Fitzgibbons and GordonSalant, 1995; Gordon-Salant and Fitzgibbons, 1999; Kumar and Sangamanatha, 2011), as well as impaired temporal order judgments (Gordon-Salant and Fitzgibbons, 1999; Fitzgibbons et al., 2006; Ulbrich et al., 2009) and temporal sequencing (Trainor and Trehub, 1989).

Within vision, many age-related temporal processing deficits have been documented, including reduced flicker sensitivity (Mayer et al., 1988; Tyler, 1989; Kuyk and Wesson, 1991; Kim and Mayer, 1994), reduced critical flicker frequency (Misiak, 1947, 1951; Coppinger, 1955; McFarland et al., 1958; Lachenmayr et al., 1994) and some impairments in motion perception (Trick and Silverman, 1991; Tran et al., 1998; Habak and Faubert, 2000; Snowden and Kavanagh, 2006; Bennett et al., 2007; Billino et al., 2008). Similar to deficits in auditory processing, there is an age-related decline in visual gap detection (Humes et al., 2009) and temporal order judgments
(Ulbrich et al., 2009; Busey et al., 2010; de Boer-Schellekens and Vroomen, 2014).

Furthermore, sensory decline is typically uneven across vision and audition, though the more adversely affected sensory modality varies between tasks (Čeponienè et al., 2008; Guerreiro and Van Gerven, 2011; Lustig and Meck, 2011; Cliff et al., 2013; Diaconescu et al., 2013; Guerreiro et al., 2013). For example, older age impairs visual duration judgments more than auditory ones (Lustig and Meck, 2011). In contrast, auditory but not visual temporal rate discriminability is poorer in older adults (Brooks et al., 2015). Consequently, for a given audiovisual task, auditory and visual cues are not expected to be equally degraded by age-related sensory changes.

\section{AGE-RELATED CHANGES IN AUDIOVISUAL TEMPORAL PERCEPTION}

Studies have investigated age-related changes to various measures of audiovisual temporal perception presumed to reflect multisensory integration, with disparate results for transient stimuli like flashes and beeps. Older adults are more susceptible to the sound-induced flash illusion (Setti et al., 2011a; DeLoss et al., 2013; McGovern et al., 2014). In this illusory fission effect, the integration of two beeps and a solitary flash results in the perception of two flashes (Shams et al., 2000). Older adults also exhibit an enhanced temporal ventriloquist effect (de Boer-Schellekens and Vroomen, 2014), in which the presentation of a click before and after a sequence of two flashes increases visual temporal order sensitivity (Morein-Zamir et al., 2003). Conversely, the integration of two flashes with a single beep results in the perception of a single flash in an illusory fusion effect (Andersen et al., 2004) that does not change in aging (McGovern et al., 2014). In the audiovisual bounce effect, an auditory beep influences a visual spatiotemporal illusion, in which two disks moving toward each other appear either to stream past one another, or less frequently, to bounce (Sekuler and Sekuler, 1999). The beep, sounding as the disks overlap, causes an increase in the frequency of perceived bouncing (Sekuler et al., 1997). This effect is reduced in older adults, suggestive of decreased integration (Roudaia et al., 2013).

Age-related effects on the integration of temporally modulated stimuli depend on audiovisual congruency. Partial integration of non-identical auditory and visual temporal rates distorts perceived rate such that the auditory or visual rate subjectively equivalent to a reference is non-veridical (Roach et al., 2006). This effect is equivalent in younger and older adults (Brooks et al., 2015). However, integration of identical auditory and visual temporal rates improves temporal rate discrimination in a statistically optimal fashion in younger (Koene et al., 2007; Brooks et al., 2015) but not older adults, who fail to show the $\sqrt{ } 2$ improvement predicted by maximum likelihood estimation (Brooks et al., 2015).

Research on audiovisual speech perception in aging is also relevant to this review, since the temporal relationships between auditory and visual speech cues (Chandrasekaran et al., 2009) 
facilitate both auditory speech detection (Grant and Seitz, 2000) and recognition (ten Oever et al., 2013; Jaekl et al., 2015). Visual facilitation of auditory speech detection is reduced in older adults (Tye-Murray et al., 2011). The effect of aging on audiovisual gains in speech recognition is more complex, with no age-related changes evident when auditory and visual speech cues are clear and congruent (Ballingham and Cienkowski, 2004; Sommers et al., 2005; Spehar et al., 2008; Gordon and Allen, 2009; Legault et al., 2010; Tye-Murray et al., 2010; Winneke and Phillips, 2011; Huyse et al., 2014; Smayda et al., 2016; Sommers and Phelps, 2016). However, audiovisual gains are reduced in older adults when auditory and visual speech cues are degraded (Tye-Murray et al., 2008, 2010, 2011; Gordon and Allen, 2009; Huyse et al., 2014; Stevenson et al., 2015) or asynchronous (Gordon-Salant et al., 2017).

In the McGurk effect, integration of incongruent auditory and visual speech results in a fused percept that matches neither cue (McGurk and Macdonald, 1976). Most studies report a similar proportion of fused responses in younger and older adult groups for syllables (Cienkowski and Carney, 2002; Ballingham and Cienkowski, 2004; Huyse et al., 2014; Stothart and Kazanina, 2016). Discrepant findings reported in the literature likely reflect differences in study design, with an agerelated increase in fused responses found when speech stimuli were words (Setti et al., 2013) and an age-related decrease in fused responses found when auditory syllables were presented in modulated noise (Huyse et al., 2014). Comparison between studies using different experimental stimuli is also complicated by known variability in the McGurk effect with different speakers (Jiang and Bernstein, 2011; Mallick et al., 2015) and different auditory and visual syllable pairings (Jiang and Bernstein, 2011).

Altogether, research indicates an age-related increase in the integration of temporally offset auditory and visual events. Older adults perceive the sound-induced flash illusion at larger temporal offsets between auditory and visual stimuli than younger adults (Setti et al., 2011a; McGovern et al., 2014). When judging synchrony, older adults perceive temporally offset auditory and visual events as simultaneous over a broader (Hay-McCutcheon et al., 2009; Noel et al., 2016), narrower (Alm and Behne, 2013) or similar (Baskent and Bazo, 2011; Bedard and Barnett-Cowan, 2016) temporal window compared to younger adults. However, the temporal window of perceived synchrony is broader in older adults when individual differences in stimulus detectability and response criterion are normalized, indicative of enhanced integration (Chan et al., 2014). Similarly, in judgments of temporal order, older adults need a larger temporal gap between an auditory and visual stimulus to distinguish which appeared first (Virsu et al., 2003; Setti et al., 2011b; de Boer-Schellekens and Vroomen, 2014; Bedard and Barnett-Cowan, 2016), but one study found no age-related differences in audiovisual temporal order judgments (Fiacconi et al., 2013). All of these temporal order studies used stimuli that were not individually scaled to detectability, and Fiacconi et al tested observers of at least 70 years of age, which is older than the inclusion criteria of the other above cited studies (at least 60 years).

In summary, integration of temporal auditory and visual information may be increased, decreased or unchanged by physiological aging (see Tables 1, 2). This suggests that age-related effects on integration may be task-specific, as discussed in the next section.

\section{TASK-SPECIFIC INTEGRATION PROCESSES}

An outstanding question is how closely audiovisual integration of temporal information is linked across different tasks. On the one hand, performance across different temporal audiovisual tasks is often correlated within individuals (Tremblay et al., 2007; Stevenson et al., 2012; Stevenson and Wallace, 2013), suggesting that different tasks can index common processes. Accordingly, older adults exhibit both increased susceptibility to the sound induced flash illusion (Setti et al., 2011a; DeLoss et al., 2013; McGovern et al., 2014) and broader temporal binding windows (Chan et al., 2014; Noel et al., 2016), consistent with the correlation between performance on these tasks in younger adults (Stevenson et al., 2012). However, within-subject correlations in younger adults have a limited potential to connect age-related effects on integration across different tasks. Correlations between tasks may reflect unisensory reliability, rather than a shared tendency to integrate, as both factors contribute to observed audiovisual interactions (Odegaard and Shams, 2016). Preliminary evidence suggests that the brain's tendency to integrate auditory and visual cues is task-specific, though it remains unclear how tightly integration tendency is linked across tasks within the same perceptual domain (Odegaard and Shams, 2016). Furthermore, while low level stimulus characteristics such as temporal correspondence and unisensory reliability modulate the strength of audiovisual interactions, the integration process is also influenced by contextually-driven factors such as task goal, attention, and learned audiovisual associations (for review see van Atteveldt et al., 2014; Tye-Murray et al., 2016).

Different tasks likely index different perceptual processes. For example, research suggests distinctions between the perception of audiovisual temporal rate and relative timing (Fujisaki and Nishida, 2005). Moreover, a complex task like audiovisual speech perception is influenced by higher level factors, such as semantic congruence and linguistic meaning, not just lower level stimulus characteristics like temporal structure (Eskelund et al., 2011; Lee and Noppeney, 2011; Stekelenburg and Vroomen, 2012; ten Oever et al., 2013; Stevenson et al., 2014). In older adults, audiovisual gains in speech recognition decrease with task complexity, such as lexical difficulty (Dey and Sommers, 2015) or whole-word compared to phoneme recognition (Stevenson et al., 2015).

Additionally, audiovisual temporal tasks may not index the same perceptual processes even with comparable stimuli, such as audiovisual speech detection and recognition 
TABLE 1 | Age-related changes in the perception of audiovisual temporal information consistent with decreased, unchanged, or increased integration in older relative to younger adults.

\begin{tabular}{|c|c|c|c|}
\hline \multirow[t]{2}{*}{ Audiovisual task } & \multicolumn{3}{|c|}{ Age-related changes in multisensory integration: } \\
\hline & Decreased & Unchanged & Increased \\
\hline Sound-induced flash fission & - & - & $\begin{array}{l}\text { Setti et al., 2011a; DeLoss et al., 2013; } \\
\text { McGovern et al., } 2014\end{array}$ \\
\hline Sound-induced flash fusion & - & McGovern et al., 2014 & - \\
\hline Temporal ventriloquist effect & - & - & $\begin{array}{l}\text { de Boer-Schellekens and Vroomen, } \\
2014\end{array}$ \\
\hline Audiovisual bounce effect & Roudaia et al., 2013 & - & - \\
\hline Identical temporal rates & Brooks et al., 2015 & - & - \\
\hline Non-identical temporal rates & - & Brooks et al., 2015 & - \\
\hline Speech detection & Tye-Murray et al., 2011 & - & - \\
\hline Speech recognition & $\begin{array}{l}\text { Tye-Murray et al., 2008, 2010, 2011; } \\
\text { Gordon and Allen, 2009; Huyse et al., } \\
\text { 2014; Stevenson et al., 2015; } \\
\text { Gordon-Salant et al., } 2017\end{array}$ & $\begin{array}{l}\text { Ballingham and Cienkowski, 2004; } \\
\text { Sommers et al., 2005; Spehar et al., } \\
\text { 2008; Gordon and Allen, 2009; Legault } \\
\text { et al., 2010; Tye-Murray et al., 2010; } \\
\text { Winneke and Phillips, 2011; Huyse } \\
\text { et al., 2014; Smayda et al., 2016; } \\
\text { Sommers and Phelps, } 2016\end{array}$ & - \\
\hline McGurk effect (fused responses) & Huyse et al., 2014 & $\begin{array}{l}\text { Cienkowski and Carney, 2002; } \\
\text { Ballingham and Cienkowski, 2004; } \\
\text { Huyse et al., 2014; Stothart and } \\
\text { Kazanina, } 2016\end{array}$ & Setti et al., 2013 \\
\hline
\end{tabular}

See text for discussion of how closely changes in perceptual measures reflect the underlying ability to integrate.

TABLE 2 | Age-related changes in the temporal binding window of auditory and visual events, indicating whether older adults were found to have narrower, unchanged, or wider temporal binding windows relative to younger adults.

\begin{tabular}{|c|c|c|c|}
\hline \multirow[t]{2}{*}{ Audiovisual task } & \multicolumn{3}{|c|}{ Age-related changes in the temporal binding window: } \\
\hline & Narrower & Unchanged & Wider \\
\hline Temporal order judgments & - & Fiacconi et al., 2013 & $\begin{array}{l}\text { Virsu et al., 2003; Setti et al., 2011b; de } \\
\text { Boer-Schellekens and Vroomen, 2014; } \\
\text { Bedard and Barnett-Cowan, } 2016\end{array}$ \\
\hline Synchrony judgments & Alm and Behne, 2013 & $\begin{array}{l}\text { Baskent and Bazo, 2011; Bedard and } \\
\text { Barnett-Cowan, } 2016\end{array}$ & $\begin{array}{l}\text { Hay-McCutcheon et al., 2009; Chan } \\
\text { et al., 2014; Noel et al., } 2016\end{array}$ \\
\hline
\end{tabular}

(Eskelund et al., 2011) and audiovisual temporal order and synchrony judgments (Love et al., 2013). In fact, estimates of the temporal binding window from temporal order and synchrony tasks are not correlated in older adults (Bedard and Barnett-Cowan, 2016). The McGurk effect is experienced at temporal offsets between auditory and visual syllables where observers are aware of the asynchrony (Soto-Faraco and Alsius, 2009), in line with differences in the neural substrate processing asynchrony and perceptual fusion for audiovisual speech (Stevenson et al., 2011). Furthermore, evidence points toward distinct cortical mechanisms of illusory flash fusion and fission (Mishra et al., 2007, 2008) that may be differentially vulnerable to age-related effects given differences in older adult susceptibility to each illusion type (McGovern et al., 2014). Likewise, older adults exhibit impaired integration of identical but not conflicting auditory and visual temporal rates, suggesting the presence of separate integration mechanisms that differ in their susceptibility to age-related decline (Brooks et al., 2015).
Lastly, there are concerns regarding the adequacy of some study measures as indices of integration. Though some argue that decisional processes drive the audiovisual bounce effect (Grove et al., 2016; Zeljko and Grove, 2016), most studies indicate that the effect is perceptual (Watanabe and Shimojo, 2001; Sanabria et al., 2004; Dufour et al., 2008; Meyerhoff and Scholl, 2018). Multiple studies suggest that the McGurk effect is an unreliable measure of integration, due to substantial individual variability (Mallick et al., 2015), underestimation of visual modulation of the auditory cue (Brancazio and Miller, 2005; Tiippana, 2014) and the contribution of individual differences in sensitivity to incongruity and lipreading skill to illusion susceptibility (Strand et al., 2014). As for audiovisual gains in speech recognition, recent analysis argues improved performance does not result from integration and that different integration measures indicate opposing agerelated effects (Tye-Murray et al., 2016). Greater understanding of the relationships between audiovisual tasks and how closely perceptual changes reflect integration is needed to clarify current research. 


\section{THE ROLE OF AGE-RELATED CHANGES IN UNISENSORY PROCESSING}

Age-related unisensory changes are a potential confounding factor in the interpretation of age-related changes in audiovisual perception. According to the principle of inverse effectiveness, if auditory and visual cues are less salient, there will be a greater proportionate change in neural responses upon their integration (Meredith and Stein, 1983). Since this principle can also apply to perception (Stein et al., 1988), apparently enhanced integration in older age may reflect reduced stimulus saliency due to age-related sensory loss (Mozolic et al., 2012; Freiherr et al., 2013). However, a relationship between sensory reliability and integration does not necessarily mean that age-related sensory loss will explain age-related differences. While lower stimulus intensities broaden temporal binding windows in younger adults (Krueger Fister et al., 2016), older adults demonstrated broader temporal binding windows than younger adults when stimulus intensity was scaled to individual detection thresholds, indicating the effect was independent of age-related declines in sensory sensitivity (Chan et al., 2014). Furthermore, counter to the predictions of inverse effectiveness, there is an age-related increase in audiovisual enhancement of word recognition at intermediate auditory signal to noise ratios (Stevenson et al., 2015) and an age-related decrease in audiovisual enhancement of degraded sentences (Tye-Murray et al., 2010). This is consistent with evidence that audiovisual gains in speech recognition are greatest for intermediate auditory clarity (Ross et al., 2007; cf. Stevenson et al., 2015).

The reliability of auditory relative to visual sensory estimates of a property (where reliability is defined as the estimate's precision, as given by the inverse of its variance) also influences audiovisual interactions (Ernst and Bülthoff, 2004). In contrast to the historical view that audition dominates temporal perception due to its superior temporal resolution (Welch and Warren, 1980), current theory holds that the brain weights a pair of sensory cues according to their relative reliability to derive the most precise multisensory representation possible from available information (Ernst and Bülthoff, 2004; Witten and Knudsen, 2005; Fetsch et al., 2013). Unisensory reliability plays a role in susceptibility to audiovisual illusions, in which information from one sensory modality modulates perception in another (e.g., Sekiyama and Tohkura, 1991; Andersen et al., 2005; Roach et al., 2006; Kumpik et al., 2014; Strand et al., 2014). Consequently, uneven age-related sensory decline could alter the relative contribution of audition and vision to the audiovisual percept, resulting in an apparent change in illusion susceptibility. Age-related shifts in the weighting of auditory and visual cues have been documented for audiovisual speech. When studies employed audiovisual speech cues that gave rise to age-related differences in unisensory performance, older adults gave more weight than younger adults to auditory (Huyse et al., 2014) or visual information (Cienkowski and Carney, 2002; Sekiyama et al., 2014; Festa et al., 2017), in accordance with the more reliable sensory modality. However, it is possible to probe age-related differences in integration capacity by individually balancing the relative reliability of auditory and visual cues, as was shown for temporal rate perception (Brooks et al., 2015).

Unfortunately, studies of audiovisual integration in older adults have not employed a consistent definition of what constitutes normal hearing and vision, and may not screen both sensory modalities for age-abnormal changes. Even so, screening measures commonly used in older adults such as audiometric thresholds and visual acuity are poor indicators of other aspects of auditory (e.g., Gordon-Salant and Fitzgibbons, 1999; Plack et al., 2014) or visual perception (e.g., Haegerstrom-Portnoy et al., 1999), respectively. The issue is further complicated by the often indistinct boundary between age-related and pathological changes (Owsley, 2011). Older age increases the prevalence of ocular diseases such as glaucoma (Quigley and Broman, 2006) and age-related macular degeneration (Friedman et al., 2004) that can further impair temporal perception even in early stages (e.g., Ansari et al., 2002; Phipps et al., 2004; Spry et al., 2005; Dimitrov et al., 2011; Gin et al., 2011). Age-related sensorineural hearing loss contributes to impaired auditory temporal perception independently from physiological aging (Gallun et al., 2014) and for stimuli at low frequencies despite normal audiometric thresholds (Feng et al., 2010). Age-related high frequency hearing loss also increases the intrinsic functional connectivity between auditory and visual cortical regions, which may increase audiovisual interactions in older adults (Puschmann and Thiel, 2017). Before drawing conclusions on how integration may change with age, studies should carefully account for age-related changes in both auditory and visual saliency on an individual basis (e.g., Chan et al., 2014; Brooks et al., 2015).

\section{CONCLUSION}

Audiovisual integration may not necessarily provide older adults with an effective compensatory mechanism for age-related unisensory decline in temporal information. While older adults often benefit from the provision of complimentary auditory and visual cues, it can be to a reduced extent compared to younger adults. Older adults sometimes demonstrate an increased tendency to synthesize conflicting temporal auditory and visual cues into a unified percept but this is not a universal finding. Further research elucidating how closely integration is linked across different audiovisual tasks is needed to clarify this pattern of results. Currently, it remains unclear to what extent age-related changes in audiovisual temporal perception reflect true changes in integration rather than sequential effects of age-related sensory loss. Future research should account for individual differences in unisensory reliability to distinguish age-related sensory loss from age-related effects on integration.

\section{AUTHOR CONTRIBUTIONS}

CB: conception and planning of review and wrote the manuscript. YC: planning of review and contributed to 
the writing of Section "Age-Related Changes in Audiovisual Temporal Perception." AM and AA: conception of review and revision of the manuscript. All authors approved the manuscript.

\section{REFERENCES}

Alm, M., and Behne, D. (2013). Audio-visual speech experience with age influences perceived audio-visual asynchrony in speech. J. Acoust. Soc. Am. 134, 3001-3010. doi: 10.1121/1.4820798

Andersen, T. S., Tiippana, K., and Sams, M. (2004). Factors influencing audiovisual fission and fusion illusions. Brain Res. Cogn. Brain Res. 21, 301-308. doi: 10.1016/j.cogbrainres.2004.06.004

Andersen, T. S., Tiippana, K., and Sams, M. (2005). Maximum likelihood integration of rapid flashes and beeps. Neurosci. Lett. 380, 155-160. doi: 10.1016/j.neulet.2005.01.030

Ansari, E. A., Morgan, J. E., and Snowden, R. J. (2002). Psychophysical characterisation of early functional loss in glaucoma and ocular hypertension. Br. J. Ophthalmol. 86, 1131-1135. doi: 10.1136/bjo.86.10.1131

Babkoff, H., and Fostick, L. (2017). Age-related changes in auditory processing and speech perception: cross-sectional and longitudinal analyses. Eur. J. Ageing 14, 269-281. doi: 10.1007/s10433-017-0410-y

Ballingham, T., and Cienkowski, K. M. (2004). Visual enhancement in consonant identification by younger and older adults. J. Acad. Rehabil. Audiol. 37, 11-21.

Baskent, D., and Bazo, D. (2011). Audiovisual asynchrony detection and speech intelligibility in noise with moderate to severe sensorineural hearing impairment. Ear Hear. 32, 582-592. doi: 10.1097/AUD.0b013e31820fca23

Bedard, G., and Barnett-Cowan, M. (2016). Impaired timing of audiovisual events in the elderly. Exp. Brain Res. 234, 331-340. doi: 10.1007/s00221-015-4466-7

Bennett, P. J., Sekuler, R., and Sekuler, A. B. (2007). The effects of aging on motion detection and direction identification. Vision Res. 47, 799-809. doi: 10.1016/j. visres.2007.01.001

Billino, J., Bremmer, F., and Gegenfurtner, K. R. (2008). Differential aging of motion processing mechanisms: evidence against general perceptual decline. Vision Res. 48, 1254-1261. doi: 10.1016/j.visres.2008.02.014

Brancazio, L., and Miller, J. L. (2005). Use of visual information in speech perception: evidence for a visual rate effect both with and without a McGurk effect. Percept. Psychophys. 67, 759-769. doi: 10.3758/BF03193531

Brooks, C. J., Anderson, A. J., Roach, N. W., McGraw, P. V., and McKendrick, A. M. (2015). Age-related changes in auditory and visual interactions in temporal rate perception. J. Vis. 15:2. doi: 10.1167/15.16.2

Busey, T., Craig, J., Clark, C., and Humes, L. (2010). Age-related changes in visual temporal order judgment performance: relation to sensory and cognitive capacities. Vision Res. 50, 1628-1640. doi: 10.1016/j.visres.2010.05.003

Čeponienė, R., Westerfield, M., Torki, M., and Townsend, J. (2008). Modalityspecificity of sensory aging in vision and audition: evidence from event-related potentials. Brain Res. 1215, 53-68. doi: 10.1016/j.brainres.2008.02.010

Chan, Y. M., Pianta, M. J., and McKendrick, A. M. (2014). Older age results in difficulties separating auditory and visual signals in time. J. Vis. 14:13. doi: $10.1167 / 14.11 .13$

Chandrasekaran, C., Trubanova, A., Stillittano, S., Caplier, A., and Ghazanfar, A. A. (2009). The natural statistics of audiovisual speech. PLoS Comput. Biol. 5:e1000436. doi: 10.1371/journal.pcbi.1000436

Cienkowski, K. M., and Carney, A. E. (2002). Auditory-visual speech perception and aging. Ear Hear. 23, 439-449. doi: 10.1097/01.aud.0000034781.95122.15

Cliff, M., Joyce, D. W., Lamar, M., Dannhauser, T., Tracy, D. K., and Shergill, S. S. (2013). Aging effects on functional auditory and visual processing using fMRI with variable sensory loading. Cortex 49, 1304-1313. doi: 10.1016/j.cortex.2012. 04.003

Conlon, E., and Herkes, K. (2008). Spatial and temporal processing in healthy aging: implications for perceptions of driving skills. Neuropsychol. Dev. Cogn. B Aging Neuropsychol. Cogn. 15, 446-470. doi: 10.1080/1382558070187 8008

Coppinger, N. W. (1955). The relationship between critical flicker frequency and chronologic age for varying levels of stimulus brightness. J. Gerontol. 10, 48-52. doi: $10.1093 /$ geronj/10.1.48

\section{FUNDING}

This study was supported by Australian Research Council (FT0990930 to AM).

de Boer-Schellekens, L., and Vroomen, J. (2014). Multisensory integration compensates loss of sensitivity of visual temporal order in the elderly. Exp. Brain Res. 232, 253-262. doi: 10.1007/s00221-0133736-5

de Dieuleveult, A. L., Siemonsma, P. C., van Erp, J. B. F., and Brouwer, A.-M. (2017). Effects of aging in multisensory integration: a systematic review. Front. Aging Neurosci. 9:80. doi: 10.3389/fnagi.2017.00080

DeLoss, D. J., Pierce, R. S., and Andersen, G. J. (2013). Multisensory integration, aging, and the sound-induced flash illusion. Psychol. Aging 28, 802-812. doi: $10.1037 / \mathrm{a} 0033289$

Denison, R. N., Driver, J., and Ruff, C. C. (2013). Temporal structure and complexity affect audio-visual correspondence detection. Front. Psychol. 3:619. doi: 10.3389/fpsyg.2012.00619

Dey, A., and Sommers, M. S. (2015). Age-related differences in inhibitory control predict audiovisual speech perception. Psychol. Aging 30, 634-646. doi: 10.1037/ pag0000033

Diaconescu, A., Diaconescu, L., Hasher, A., and McIntosh, A. R. (2013). Visual dominance and multisensory integration changes with age. Neuroimage 65, 152-166. doi: 10.1016/j.neuroimage.2012.09.057

Dimitrov, P. N., Robman, L. D., Varsamidis, M., Aung, K. Z., Makeyeva, G. A., Guymer, R. H., et al. (2011). Visual function tests as potential biomarkers in age-related macular degeneration. Invest. Ophthalmol. Vis. Sci. 52, 9457-9469. doi: 10.1167/iovs.10-7043

Dufour, A., Touzalin, P., Moessinger, M., Brochard, R., and Després, O. (2008). Visual motion disambiguation by a subliminal sound. Conscious. Cogn. 17, 790-797. doi: 10.1016/j.concog.2007.09.001

Ernst, M. O., and Bülthoff, H. H. (2004). Merging the senses into a robust percept. Trends Cogn. Sci. 8, 162-169. doi: 10.1016/j.tics.2004.02.002

Eskelund, K., Tuomainen, J., and Andersen, T. S. (2011). Multistage audiovisual integration of speech: dissociating identification and detection. Exp. Brain Res. 208, 447-457. doi: 10.1007/s00221-010-2495-9

Feng, Y., Yin, S., Kiefte, M., and Wang, J. (2010). Temporal resolution in regions of normal hearing and speech perception in noise for adults with sloping high-frequency hearing loss. Ear Hear. 31, 115-125. doi: 10.1097/AUD. ob013e3181bb69be

Festa, E. K., Katz, A. P., Ott, B. R., Tremont, G., and Heindel, W. C. (2017). Dissociable effects of aging and mild cognitive impairment on bottom-up audiovisual integration. J. Alzheimers Dis. 59, 155-167. doi: 10.3233/JAD161062

Fetsch, C. R., DeAngelis, G. C., and Angelaki, D. E. (2013). Bridging the gap between theories of sensory cue integration and the physiology of multisensory neurons. Nat. Rev. Neurosci. 14, 429-442. doi: 10.1038/nrn3503

Fiacconi, C. M., Harvey, E. C., Sekuler, A. B., and Bennett, P. J. (2013). The influence of aging on audiovisual temporal order judgments. Exp. Aging Res. 39, 179-193. doi: 10.1080/0361073X.2013.761896

Fitzgibbons, P. J., and Gordon-Salant, S. (1994). Age effects on measures of auditory duration discrimination. J. Speech Hear. Res. 37, 662-670. doi: 10.1044/ jshr.3703.662

Fitzgibbons, P. J., and Gordon-Salant, S. (1995). Age effects on duration discrimination with simple and complex stimuli. J. Acoust. Soc. Am. 98, 3140-3145. doi: 10.1121/1.413803

Fitzgibbons, P. J., Gordon-Salant, S., and Friedman, S. A. (2006). Effects of age and sequence presentation rate on temporal order recognition. J. Acoust. Soc. Am. 120, 991-999. doi: 10.1121/1.2214463

Freiherr, J., Lundström, J. N., Habel, U., and Reetz, K. (2013). Multisensory integration mechanisms during aging. Front. Hum. Neurosci. 7:863. doi: $10.3389 /$ fnhum.2013.00863

Friedman, D. S., Wolfs, R. C., O'Colmain, B. J., Klein, B. E., Taylor, H. R., West, S., et al. (2004). Prevalence of age-related macular degeneration in the United States. Arch. Ophthalmol. 122, 564-572. doi: 10.1001/archopht.122. 4.564 
Fujisaki, W., and Nishida, S. (2005). Temporal frequency characteristics of synchrony-asynchrony discrimination of audio-visual signals. Exp. Brain Res. 166, 455-464. doi: 10.1007/s00221-005-2385-8

Füllgrabe, C. (2013). Age-dependent changes in temporal-fine-structure processing in the absence of peripheral hearing loss. Am. J. Audiol. 22, 313-315. doi: 10.1044/1059-0889(2013/12-0070

Füllgrabe, C., Moore, B. C. J., and Stone, M. A. (2014). Age-group differences in speech identification despite matched audiometrically normal hearing: contributions from auditory temporal processing and cognition. Front. Aging Neurosci. 6:347. doi: 10.3389/fnagi.2014.00347

Gallun, F. J., McMillan, G. P., Molis, M. R., Kampel, S. D., Dann, S. M., and KonradMartin, D. L. (2014). Relating age and hearing loss to monaural, bilateral, and binaural temporal sensitivity. Front. Neurosci. 8:172. doi: 10.3389/fnins.2014. 00172

Gin, T. J., Luu, C. D., and Guymer, R. H. (2011). Central retinal function as measured by the multifocal electroretinogram and flicker perimetry in early age-related macular degeneration. Invest. Ophthalmol. Vis. Sci. 52, 9267-9274. doi: $10.1167 /$ iovs.11-8517

Gordon, M. S., and Allen, S. (2009). Audiovisual speech in older and younger adults: integrating a distorted visual signal with speech in noise. Exp. Aging Res. 35, 202-219. doi: 10.1080/03610730902720398

Gordon-Salant, S., and Fitzgibbons, P. J. (1993). Temporal factors and speech recognition performance in young and elderly listeners. J. Speech Lang. Hear. Res. 36, 1276-1285. doi: 10.1044/jshr.3606.1276

Gordon-Salant, S., and Fitzgibbons, P. J. (1999). Profile of auditory temporal processing in older listeners. J. Speech Lang. Hear. Res. 42, 300-311. doi: $10.1044 /$ jslhr. 4202.300

Gordon-Salant, S., Yeni-Komshian, G. H., Fitzgibbons, P. J., Willison, H. M., and Freund, M. S. (2017). Recognition of asynchronous auditory-visual speech by younger and older listeners: a preliminary study. J. Acoust. Soc. Am. 142, 151-159. doi: 10.1121/1.4992026

Grant, K. W., and Seitz, P.-F. (2000). The use of visible speech cues for improving auditory detection of spoken sentences. J. Acoust. Soc. Am. 108, 1197-1208. doi: $10.1121 / 1.1288668$

Grose, J. H., and Mamo, S. K. (2010). Processing of temporal fine structure as a function of age. Ear Hear. 31, 755-760. doi: 10.1097/AUD.0b013e3181e627e7

Grose, J. H., and Mamo, S. K. (2012). Frequency modulation detection as a measure of temporal processing: age-related monaural and binaural effects. Hear. Res. 294, 49-54. doi: 10.1016/j.heares.2012.09.007

Grove, P. M., Robertson, C., and Harris, L. R. (2016). Disambiguating the stream/bounce illusion with inference. Multisens. Res. 29, 453-464 doi: $10.1163 / 22134808-00002524$

Guerreiro, M. J. S., Murphy, D. R., and Van Gerven, P. W. M. (2013). Making sense of age-related distractibility: the critical role of sensory modality. Acta Psychol. 142, 184-194. doi: 10.1016/j.actpsy.2012.11.007

Guerreiro, M. J. S., and Van Gerven, P. W. M. (2011). Now you see it, now you don't: evidence for age-dependent and age-independent cross-modal distraction. Psychol. Aging 26, 415-426. doi: 10.1037/a0021507

Habak, C., and Faubert, J. (2000). Larger effect of aging on the perception of higher-order stimuli. Vision Res. 40, 943-950. doi: 10.1016/S0042-6989(99) 00235-7

Haegerstrom-Portnoy, G., Schneck, M. E., and Brabyn, J. A. (1999). Seeing into old age: vision function beyond acuity. Optom. Vis. Sci. 76, 141-158. doi: 10.1097/ 00006324-199903000-00014

Hay-McCutcheon, M. J., Pisoni, D. B., and Hunt, K. K. (2009). Audiovisual asynchrony detection and speech perception in hearing-impaired listeners with cochlear implants: a preliminary analysis. Int. J. Audiol. 48, 321-333. doi: $10.1080 / 14992020802644871$

He, N. J., Mills, J. H., Ahlstrom, J. B., and Dubno, J. R. (2008). Agerelated differences in the temporal modulation transfer function with pure-tone carriers. J. Acoust. Soc. Am. 124, 3841-3849. doi: 10.1121/1.299 8779

He, N. J., Mills, J. H., and Dubno, J. R. (2007). Frequency modulation detection: effects of age, psychophysical method, and modulation waveform. J. Acoust. Soc. Am. 122, 467-477. doi: 10.1121/1.2741208

Heinrich, A., and Schneider, B. (2006). Age-related changes in within- and between-channel gap detection using sinusoidal stimuli. J. Acoust. Soc. Am. 119, 2316-2326. doi: 10.1121/1.2173524
Humes, L. E., Busey, T. A., Craig, J. C., and Kewley-Port, D. (2009). The effects of age on sensory thresholds and temporal gap detection in hearing, vision, and touch. Atten. Percept. Psychophys. 71, 860-871. doi: 10.3758/APP.71.4.860

Huyse, A., Leybaert, J., and Berthommier, F. (2014). Effects of aging on audio-visual speech integration. J. Acoust. Soc. Am. 136, 1918-1931. doi: 10.1121/1.4894685

Jaekl, P., Pesquita, A., Alsius, A., Munhall, K., and Soto-Faraco, S. (2015). The contribution of dynamic visual cues to audiovisual speech perception. Neuropsychologia 75, 402-410. doi: 10.1016/j.neuropsychologia.2015.06.025

Jiang, J., and Bernstein, L. E. (2011). Psychophysics of the McGurk and other audiovisual speech integration effects. J. Exp. Psychol. Hum. Percept. Perform. 37, 1193-1209. doi: 10.1037/a0023100

Kim, C. B., and Mayer, M. J. (1994). Foveal flicker sensitivity in healthy aging eyes. II. Cross-sectional aging trends from 18 through 77 years of age. J. Opt. Soc. Am. A Opt. Image Sci. Vis. 11, 1958-1969. doi: 10.1364/JOSAA.11.001958

Koene, A., Arnold, D., and Johnston, A. (2007). Bimodal sensory discrimination is finer than dual single modality discrimination. J. Vis. 7:14. doi: 10.1167/7.11.14

Krueger Fister, J., Stevenson, R. A., Nidiffer, A. R., Barnett, Z. P., and Wallace, M. T. (2016). Stimulus intensity modulates multisensory temporal processing. Neuropsychologia 88, 92-100. doi: 10.1016/j.neuropsychologia.2016.02.016

Kumar, A. U., and Sangamanatha, A. V. (2011). Temporal processing abilities across different age groups. J. Am. Acad. Audiol. 22, 5-12. doi: 10.3766/jaaa. 22.1 .2

Kumpik, D. P., Roberts, H. E., King, A. J., and Bizley, J. K. (2014). Visual sensitivity is a stronger determinant of illusory processes than auditory cue parameters in the sound-induced flash illusion. J. Vis. 14:12. doi: 10.1167/14.7.12

Kuyk, T. K., and Wesson, M. D. (1991). Aging-related foveal flicker sensitivity losses in normal observers. Optom. Vis. Sci. 68, 786-789. doi: 10.1097/ 00006324-199110000-00005

Lachenmayr, B. J., Kojetinsky, S., Ostermaier, N., Angstwurm, K., Vivell, P. M., and Schaumberger, M. (1994). The different effects of aging on normal sensitivity in flicker and light-sense perimetry. Invest. Ophthalmol. Vis. Sci. 35, 2741-2748

Lacherez, P., Turner, L., Lester, R., Burns, Z., and Wood, J. M. (2014). Age-related changes in perception of movement in driving scenes. Ophthalmic Physiol. Opt. 34, 445-451. doi: 10.1111/opo.12140

Lee, H., and Noppeney, U. (2011). Physical and perceptual factors shape the neural mechanisms that integrate audiovisual signals in speech comprehension. J. Neurosci. 31, 11338-11350. doi: 10.1523/ineurosci.6510-10.2011

Legault, I., Gagné, J. P., Rhoualem, W., and Anderson-Gosselin, P. (2010). The effects of blurred vision on auditory-visual speech perception in younger and older adults. Int. J. Audiol. 49, 904-911. doi: 10.3109/14992027.2010.509112

Lewald, J., and Guski, R. (2003). Cross-modal perceptual integration of spatially and temporally disparate auditory and visual stimuli. Brain Res. Cogn. Brain Res. 16, 468-478. doi: 10.1016/S0926-6410(03)00074-0

Love, S. A., Petrini, K., Cheng, A., and Pollick, F. E. (2013). A psychophysical investigation of differences between synchrony and temporal order judgments. PLoS One 8:e54798. doi: 10.1371/journal.pone.0054798

Lustig, C., and Meck, W. H. (2011). Modality differences in timing and temporal memory throughout the lifespan. Brain Cogn. 77, 298-303. doi: 10.1016/j. bandc.2011.07.007

Mallick, D. B., Magnotti, J. F., and Beauchamp, M. S. (2015). Variability and stability in the McGurk effect: contributions of participants, stimuli, time, and response type. Psychon. Bull. Rev. 22, 1299-1307. doi: 10.3758/s13423-0150817-4

Mayer, M. J., Glucs, A., Kim, C. B. Y., and Svingos, A. (1988). Foveal flicker sensitivity in healthy aging eyes. I. Compensating for pupil variation. J. Opt. Soc. Am. A 5, 2201-2209. doi: 10.1364/JOSAA.5.002201

McFarland, R. A., Warren, A. B., and Karis, C. (1958). Alterations in critical flicker frequency as a function of age and light: dark ratio. J. Exp. Psychol. 56, 529-538. doi: 10.1037/h0049128

McGovern, D. P., Roudaia, E., Stapleton, J., McGinnity, T. M., and Newell, F. N. (2014). The sound-induced flash illusion reveals dissociable age-related effects in multisensory integration. Front. Aging Neurosci. 6:250. doi: 10.3389/fnagi. 2014.00250

McGurk, H., and Macdonald, J. (1976). Hearing lips and seeing voices. Nature 264, 746-748 doi: 10.1038/264746a0

Meredith, M., and Stein, B. (1983). Interactions among converging sensory inputs in the superior colliculus. Science 221, 389-391. doi: 10.1126/science.6867718 
Meyerhoff, H. S., and Scholl, B. J. (2018). Auditory-induced bouncing is a perceptual (rather than a cognitive) phenomenon: evidence from illusory crescents. Cognition 170, 88-94. doi: 10.1016/j.cognition.2017.08.007

Mishra, J., Martinez, A., and Hillyard, S. A. (2008). Cortical processes underlying sound-induced flash fusion. Brain Res. 1242, 102-115. doi: 10.1016/j.brainres. 2008.05.023

Mishra, J., Martinez, A., Sejnowski, T. J., and Hillyard, S. A. (2007). Early crossmodal interactions in auditory and visual cortex underlie a sound-induced visual illusion. J. Neurosci. 27, 4120-4131. doi: 10.1523/JNEUROSCI.4912-06. 2007

Misiak, H. (1947). Age and sex differences in critical flicker frequency. J. Exp. Psychol. 37, 318-332. doi: 10.1037/h0061531

Misiak, H. (1951). The decrease of critical flicker frequency with age. Science 113, 551-552. doi: 10.1126/science.113.2941.551

Moore, B. C. J., Vickers, D. A., and Mehta, A. (2012). The effects of age on temporal fine structure sensitivity in monaural and binaural conditions. Int. J. Audiol. 51, 715-721. doi: 10.3109/14992027.2012.690079

Morein-Zamir, S., Soto-Faraco, S., and Kingstone, A. (2003). Auditory capture of vision: examining temporal ventriloquism. Brain Res. Cogn. Brain Res. 17, 154-163. doi: 10.1016/S0926-6410(03)00089-2

Mozolic, J. L., Hugenschmidt, C. E., Peiffer, A. M., and Laurienti, P. J. (2012). "Integration in aging," in The Neural Bases of Multisensory Processes, eds M. M. Murray and M. T. Wallace (Boca Raton, FL: CRC Press), 381-394.

Noel, J.-P., De Niear, M., Van der Burg, E., and Wallace, M. T. (2016). Audiovisual simultaneity judgment and rapid recalibration throughout the lifespan. PLoS One 11:e0161698. doi: 10.1371/journal.pone.0161698

Odegaard, B., and Shams, L. (2016). The brain's tendency to bind audiovisual signals is stable but not general. Psychol. Sci. 27, 583-591. doi: 10.1177/ 0956797616628860

Owsley, C. (2011). Aging and vision. Vision Res. 51, 1610-1622. doi: 10.1016/j. visres.2010.10.020

Parise, C. V., Spence, C., and Ernst, M. O. (2012). When correlation implies causation in multisensory integration. Curr. Biol. 22, 46-49. doi: 10.1016/j.cub. 2011.11.039

Phipps, J. A., Dang, T. M., Vingrys, A. J., and Guymer, R. H. (2004). Flicker perimetry losses in age-related macular degeneration. Invest. Ophthalmol. Vis. Sci. 45, 3355-3360. doi: 10.1167/iovs.04-0253

Plack, C. J., Barker, D., and Prendergast, G. (2014). Perceptual consequences of "hidden" hearing loss. Trends Hear. 18:2331216514550621. doi: 10.1177/ 2331216514550621

Puschmann, S., and Thiel, C. M. (2017). Changed crossmodal functional connectivity in older adults with hearing loss. Cortex 86, 109-122. doi: 10.1016/ j.cortex.2016.10.014

Quigley, H. A., and Broman, A. T. (2006). The number of people with glaucoma worldwide in 2010 and 2020. Br. J. Ophthalmol. 90, 262-267. doi: 10.1136/bjo. 2005.081224

Ramkhalawansingh, R., Keshavarz, B., Haycock, B., Shahab, S., and Campos, J. L. (2016). Age differences in visual-auditory self-motion perception during a simulated driving task. Front. Psychol. 7:595. doi: 10.3389/fpsyg.2016. 00595

Roach, N. W., Heron, J., and McGraw, P. V. (2006). Resolving multisensory conflict: a strategy for balancing the costs and benefits of audio-visual integration. Proc. R. Soc. B Biol. Sci. 273, 2159-2168. doi: 10.1098/rspb.2006. 3578

Ross, L. A., Saint-Amour, D., Leavitt, V. M., Javitt, D. C., and Foxe, J. J. (2007). Do you see what I am saying? Exploring visual enhancement of speech comprehension in noisy environments. Cereb. Cortex 17, 1147-1153. doi: 10. 1093/cercor/bhl024

Roudaia, E., Sekuler, A. B., Bennett, P. J., and Sekuler, R. (2013). Aging and audiovisual and multi-cue integration in motion. Front. Psychol. 4:267. doi: 10.3389/ fpsyg.2013.00267

Sanabria, D., Correa, Á., Lupiáñez, J., and Spence, C. (2004). Bouncing or streaming? Exploring the influence of auditory cues on the interpretation of ambiguous visual motion. Exp. Brain Res. 157, 537-541. doi: 10.1007/s00221004-1993-z

Sekiyama, K., Soshi, T., and Sakamoto, S. (2014). Enhanced audiovisual integration with aging in speech perception: a heightened McGurk effect in older adults. Front. Psychol. 5:323. doi: 10.3389/fpsyg.2014.00323
Sekiyama, K., and Tohkura, Y. I. (1991). McGurk effect in non-English listeners: few visual effects for Japanese subjects hearing Japanese syllables of high auditory intelligibility. J. Acoust. Soc. Am. 90, 1797-1805. doi: 10.1121/1. 401660

Sekuler, A. B., and Sekuler, R. (1999). Collisions between moving visual targets: what controls alternative ways of seeing an ambiguous display? Perception 28 , 415-432. doi: 10.1068/p2909

Sekuler, R., Sekuler, A. B., and Lau, R. (1997). Sound alters visual motion perception. Nature 385:308. doi: 10.1038/385308a0

Setti, A., Burke, K. E., Kenny, R., and Newell, F. N. (2013). Susceptibility to a multisensory speech illusion in older persons is driven by perceptual processes. Front. Psychol. 4:575. doi: 10.3389/fpsyg.2013.00575

Setti, A., Burke, K. E., Kenny, R. A., and Newell, F. N. (2011a). Is inefficient multisensory processing associated with falls in older people? Exp. Brain Res. 209, 375-384. doi: 10.1007/s00221-011-2560-z

Setti, A., Finnigan, S., Sobolewski, R., McLaren, L., Robertson, I. H., Reilly, R. B., et al. (2011b). Audiovisual temporal discrimination is less efficient with aging: an event-related potential study. Neuroreport 22, 554-558. doi: 10.1097/WNR. 0b013e328348c731

Shams, L., Kamitani, Y., and Shimojo, S. (2000). Illusions: what you see is what you hear. Nature 408, 788-788. doi: 10.1038/35048669

Smayda, K. E., Van Engen, K. J., Maddox, W. T., and Chandrasekaran, B. (2016). Audio-visual and meaningful semantic context enhancements in older and younger adults. PLoS One 11:e0152773. doi: 10.1371/journal.pone.0152773

Snell, K. B. (1997). Age-related changes in temporal gap detection. J. Acoust. Soc. Am. 101, 2214-2220. doi: 10.1121/1.418205

Snowden, R. J., and Kavanagh, E. (2006). Motion perception in the ageing visual system: minimum motion, motion coherence, and speed discrimination thresholds. Perception 35, 9-24. doi: 10.1068/p5399

Sommers, M. S., and Phelps, D. (2016). Listening effort in younger and older adults: a comparison of auditory-only and auditory-visual presentations. Ear Hear. 37, 62S-68S. doi: 10.1097/aud.0000000000000322

Sommers, M. S., Tye-Murray, N., and Spehar, B. (2005). Auditory-visual speech perception and auditory-visual enhancement in normal-hearing younger and older adults. Ear Hear. 26, 263-275. doi: 10.1097/00003446-200506000-00003

Soto-Faraco, S., and Alsius, A. (2009). Deconstructing the McGurk-MacDonald illusion. J. Exp. Psychol. Hum. Percept. Perform. 35, 580-587. doi: 10.1037/ a0013483

Spehar, B. P., Tye-Murray, N., and Sommers, M. S. (2008). Intra-versus intermodal integration in young and older adults. J. Acoust. Soc. Am. 123, 2858-2866. doi: $10.1121 / 1.2890748$

Spry, P. G. D., Johnson, C. A., Mansberger, S. L., and Cioffi, G. A. (2005). Psychophysical investigation of ganglion cell loss in early glaucoma. J. Glaucoma 14, 11-19. doi: 10.1097/01.ijg.0000145813.46848.b8

Stein, B., Stanford, T., Ramachandran, R., Perrault, T. Jr., and Rowland, B. (2009). Challenges in quantifying multisensory integration: alternative criteria, models, and inverse effectiveness. Exp. Brain Res. 198, 113-126. doi: 10.1007/s00221009-1880-8

Stein, B. E., Scott Huneycutt, W., and Alex Meredith, M. (1988). Neurons and behavior: the same rules of multisensory integration apply. Brain Res. 448, 355-358. doi: 10.1016/0006-8993(88)91276-0

Stekelenburg, J. J., and Vroomen, J. (2012). Electrophysiological evidence for a multisensory speech-specific mode of perception. Neuropsychologia 50, 1425-1431. doi: 10.1016/j.neuropsychologia.2012.02.027

Stevenson, R. A., Nelms, C. E., Baum, S. H., Zurkovsky, L., Barense, M. D., Newhouse, P. A., et al. (2015). Deficits in audiovisual speech perception in normal aging emerge at the level of whole-word recognition. Neurobiol. Aging 36, 283-291. doi: 10.1016/j.neurobiolaging.2014.08.003

Stevenson, R. A., VanDerKlok, R. M., Pisoni, D. B., and James, T. W. (2011). Discrete neural substrates underlie complementary audiovisual speech integration processes. Neuroimage 55, 1339-1345. doi: 10.1016/j.neuroimage. 2010.12.063

Stevenson, R. A., and Wallace, M. T. (2013). Multisensory temporal integration: task and stimulus dependencies. Exp. Brain Res. 227, 249-261. doi: 10.1007/ s00221-013-3507-3

Stevenson, R. A., Wallace, M. T., and Altieri, N. (2014). The interaction between stimulus factors and cognitive factors during multisensory integration of audiovisual speech. Front. Psychol. 5:352. doi: 10.3389/fpsyg.2014.00352 
Stevenson, R. A., Zemtsov, R. K., and Wallace, M. T. (2012). Individual differences in the multisensory temporal binding window predict susceptibility to audiovisual illusions. J. Exp. Psychol. Hum. Percept. Perform. 38, 1517-1529. doi: $10.1037 / \mathrm{a} 0027339$

Stothart, G., and Kazanina, N. (2016). Auditory perception in the aging brain: the role of inhibition and facilitation in early processing. Neurobiol. Aging 47, 23-34. doi: 10.1016/j.neurobiolaging.2016.06.022

Strand, J., Cooperman, A., Rowe, J., and Simenstad, A. (2014). Individual differences in susceptibility to the McGurk effect: links with lipreading and detecting audiovisual incongruity. J. Speech Lang. Hear. Res. 57, 2322-2331. doi: 10.1044/2014_JSLHR-H-14-0059

Strouse, A., Ashmead, D. H., Ohde, R. N., and Grantham, D. W. (1998). Temporal processing in the aging auditory system. J. Acoust. Soc. Am. 104, 2385-2399. doi: $10.1121 / 1.423748$

Takahashi, G. A., and Bacon, S. P. (1992). Modulation detection, modulation masking, and speech understanding in noise in the elderly. J. Speech Hear. Res. 35, 1410-1421. doi: 10.1044/jshr.3506.1410

ten Oever, S., Sack, A. T., Wheat, K. L., Bien, N., and van Atteveldt, N. (2013). Audio-visual onset differences are used to determine syllable identity for ambiguous audio-visual stimulus pairs. Front. Psychol. 4:331. doi: 10.3389/ fpsyg.2013.00331

Tiippana, K. (2014). What is the McGurk effect? Front. Psychol. 5:725. doi: 10.3389/ fpsyg.2014.00725

Trainor, L. J., and Trehub, S. E. (1989). Aging and auditory temporal sequencing: ordering the elements of repeating tone patterns. Percept. Psychophys. 45, 417-426. doi: 10.3758/bf03210715

Tran, D. B., Silverman, S. E., Zimmerman, K., and Feldon, S. E. (1998). Age-related deterioration of motion perception and detection. Graefes Arch. Clin. Exp. Ophthalmol. 236, 269-273. doi: 10.1007/s00417005 0076

Tremblay, C., Champoux, F., Bacon, B. A., and Théoret, H. (2007). Evidence for a generic process underlying multisensory integration. Open Behav. Sci. J. 1, 1-4. doi: 10.2174/1874230000701010001

Trick, G. L., and Silverman, S. E. (1991). Visual sensitivity to motion: age-related changes and deficits in senile dementia of the Alzheimer type. Neurology 41, 1437-1440. doi: 10.1212/WNL.41.9.1437

Tye-Murray, N., Sommers, M., Spehar, B., Myerson, J., and Hale, S. (2010). Aging, audiovisual integration, and the principle of inverse effectiveness. Ear Hear. 31, 636-644. doi: 10.1097/AUD.0b013e3181ddf7ff

Tye-Murray, N., Sommers, M., Spehar, B., Myerson, J., Hale, S., and Rose, N. S. (2008). Auditory-visual discourse comprehension by older and young adults in favorable and unfavorable conditions. Int. J. Audiol. 47, S31-S37. doi: 10.1080/ 14992020802301662

Tye-Murray, N., Spehar, B., Myerson, J., Hale, S., and Sommers, M. (2016). Lipreading and audiovisual speech recognition across the adult lifespan: implications for audiovisual integration. Psychol. Aging 31, 380-389. doi: $10.1037 /$ pag0000094
Tye-Murray, N., Spehar, B., Myerson, J., Sommers, M. S., and Hale, S. (2011). Cross-modal enhancement of speech detection in young and older adults: does signal content matter? Ear Hear. 32, 650-655. doi: 10.1097/AUD. 0b013e31821a4578

Tyler, C. W. (1989). Two processes control variations in flicker sensitivity over the life span. J. Opt. Soc. Am. A 6, 481-490. doi: 10.1364/JOSAA.6.000481

Ulbrich, P., Churan, J., Fink, M., and Wittmann, M. (2009). Perception of temporal order: the effects of age, sex, and cognitive factors. Aging Neuropsychol. Cogn. 16, 183-202. doi: 10.1080/13825580802411758

van Atteveldt, N., Murray, M. M., Thut, G., and Schroeder, C. E. (2014). Multisensory integration: flexible use of general operations. Neuron 81, 1240-1253. doi: 10.1016/j.neuron.2014.02.044

Virsu, V., Lahti-Nuuttila, P., and Laasonen, M. (2003). Crossmodal temporal processing acuity impairment aggravates with age in developmental dyslexia. Neurosci. Lett. 336, 151-154. doi: 10.1016/s0304-3940(02)01253-3

Wallaert, N., Moore, B. C. J., and Lorenzi, C. (2016). Comparing the effects of age on amplitude modulation and frequency modulation detection. J. Acoust. Soc. Am. 139, 3088-3096. doi: 10.1121/1.4953019

Watanabe, K., and Shimojo, S. (2001). Postcoincidence trajectory duration affects motion event perception. Percept. Psychophys. 63, 16-28. doi: 10.3758/ bf03200498

Welch, R. B., and Warren, D. H. (1980). Immediate perceptual response to intersensory discrepancy. Psychol. Bull. 88, 638-667. doi: 10.1037/0033-2909. 88.3.638

Winneke, A. H., and Phillips, N. A. (2011). Does audiovisual speech offer a fountain of youth for old ears? An event-related brain potential study of age differences in audiovisual speech perception. Psychol. Aging 26, 427-438. doi: 10.1037/ a0021683

Witten, I. B., and Knudsen, E. I. (2005). Why seeing is believing: merging auditory and visual worlds. Neuron 48, 489-496. doi: 10.1016/j.neuron.2005.10.020

Wood, J. M. (2002). Age and visual impairment decrease driving performance as measured on a closed-road circuit. Hum. Factors 44, 482-494. doi: 10.1518/ 0018720024497664

Zeljko, M., and Grove, P. M. (2016). Sensitivity and bias in the resolution of streambounce stimuli. Perception 46, 178-204. doi: 10.1177/0301006616672548

Conflict of Interest Statement: The authors declare that the research was conducted in the absence of any commercial or financial relationships that could be construed as a potential conflict of interest.

Copyright (c) 2018 Brooks, Chan, Anderson and McKendrick. This is an open-access article distributed under the terms of the Creative Commons Attribution License (CC BY). The use, distribution or reproduction in other forums is permitted, provided the original author(s) and the copyright owner are credited and that the original publication in this journal is cited, in accordance with accepted academic practice. No use, distribution or reproduction is permitted which does not comply with these terms. 